\title{
Algo sobre Enrique Nieto
}

Francisco Saro Gandarillas

No anda Melilla sobrada de personajes locales a los que se recuerde asiduamente, y algunos de los que por excepción gozan de tal privilegio apenas si han contribuido en mi opinión, a merecer tal reconocimiento.

Entre los más olvidados, si alguna vez fueron recordados, están aquel puñado de hombres que con su discreta actuación pusieron algunos jalones en la no lenta expansión urbana de la ciudad. Expansión acelcrada si pensamos que, en su estructura básica, Melilla se levantó en un espacio de tiempo no superior a los veinte años. Nos estamos refiriendo, por supuesto, a los barrios centrales y principales barrios exteriores.

Entre los que, por suerte, no han pasado al olvido, se encuentra el arquitecto Enrique Nieto, quien para desgracia de otros elementos humanos fundamentales en la configuración urbanística local, ha gozado en los últimos tiempos de muy buena prensa y de una publicidad no desdeñable, acaparando la atención que, en estricta justicia hubiese debido compartir con otros personajes también dignos de atención.

Por supuesto, Enrique Nieto se lo merece, en eso no puede caber ninguna duda; lo que no significa que no haya llegado ya la hora de poner en su lugar a aquellos otros, pocos, es verdad, que junto con él contribuyeron a dejarnos esta ciudad todavía armónica en la que por este simple hecho sería delicioso vivir... si estuviera bien conservada.

Es un lugar común generalmente admitido que Enrique Nieto es el autor de la configuración urbana de Melilla. Admitir esto supone tener un concepto muy parcial de la realidad, pues solamente desde el punto de vista estético puede considerarse que Nieto es uno de los principales protagonistas, el mejor sin duda. Pero en el urbanismo coinciden elementos históricos, económicos, culturales y oficiales que no son menos importantes a la hora de hacer un juicio amplio sobre tal cuestión. Dentro de los elementos oficiales u "oficialistas", por ejemplo, la voluntad expresa de las autoridades locales, como punto de arranque de un planteamiento urbanístico, es capital. En este sentido hemos de contar siempre, como iniciadores de la expansión urbana de Melilla, con los antiguos gobernadores militares, presidentes natos de la Junta de Arbitrios, y con los olvidados ingenieros militares, como plasmadores de la voluntad de aquellos en proyectos o planes concretos de urbanización. Unos y otros han sido y son con frecuencia desdeñados cuando se habla de Melilla y su específico urbanismo, que con rara unanimidad se atribuye a Nieto en lamentable tergiversación de la realidad.

¿Acaso pierde algo Nieto por que ello no fuera así? En absoluto. Nieto ocupa el lugar que le corresponde, lugar de excepción, como arquitecto constructor, aunque el diseño urbano corresponda a otros hombres a los que no podemos olvidar; acertados o no en sus planteamientos, que eso ya sería otra cuestión. 
¿Quién era Enrique Nieto? Extraño y misterioso personaje del que solamente conocemos rasgos deshilvanados, pocos consistentes y, en gran parte, erróneos.

De su vida anterior a la llegada a Melilla apenas si sabemos algo. Nacido en Barcelona en 1884, al parecer estudió Arquitectura en esa ciudad, colaborando con Gaudí durante tres años después de terminados sus estudios.

Al parecer, al menos así lo aseguran algunos de sus familiares, tuvo ciertas discrepancias de criterio con el genial arquitecto catalán, por lo que en 1909 tomó la decisión de abandonarlo y venirse a Melilla.

¿Por qué a Melilla? Esta es una incógnita que no resulta fácil de resolver si creemos que no tenía ninguna vinculación personal o familiar con la ciudad. ¿Conoció Nieto que Melilla estaba en inicial proceso de expansión? Por supuesto, es preciso abandonar la idea de su relación con las dramáticas jomadas de la "Semana Trágica", pues Nieto se anuncia en la prensa local - "El Telegrama del Rif"- desde el 23 de junio de 1909, fecha anterior al inicio de la campaña del Rif, motivo inmediato de la famosa "Semana". El Sr. Tarragó, en su interesante pero equivocado - desde el punto de vista histórico y social- trabajo inserto en la conocida Memoria de la Cátedra Gaudi, no nos aclara nada al respecto.

Ahora bien, si creemos, como asegura su nieta Fany Nieto, que el arquitecto llegó ya casado de Barcelona, entonces el misterio se nos aclara y desvela de inmediato, puesto que Josefa Rivas Acuña, su primera mujer, tenía en Melilla, al menos desde dos afios antes, a su padre y hermano; ambos regentaban un café en el ya desaparecido Muro X. El segundo, Antonio Rivas Acufia, practicante a su vez, fue dueño durante la campaña 1909-10 del café-bar "La Inglesa", en el $n^{2} 1$ de la calle Chacel (actual Avenida), lugar de reunión de periodistas durante los sucesos de aquellos años. De aquí se puede deducir que fueron su suegro y cunado quienes le animaron a venir a Melilla, ciudad con un futuro muy prometedor para un arquitecto casi novel y, por añadidura, monopolista durante casi veinte años del título de tal.

Nieto llegó en el momento preciso, aunque él no lo supiera. Con la campaña de 1909 la población de Melilla se incrementa hasta alcanzar los casi veinte mil habitantes ocho mil más de los existentes a principios de año. La demanda de alojamiento es muy superior a las disponibilidades existentes del mismo, por lo que la construcción alcanza un ritmo frenético. Es preciso tener en cuenta, sin embargo, que cuando Nieto llega ya estaba construido, al menos, el cincuenta por ciento de lo que hoy es el centro urbano.

Desconozco cual fue el primer trabajo encomendado a nuestro personaje. Particularmente creo que uno de los primeros debió ser el primer edificio de "La Reconquista", iniciado, nada más comenzar la campaña, por el señor Brunet, catalán adinerado, que vio las inmesas posibilidades de la ciudad a corto plazo. Enrique Nieto era socio comanditario de la sociedad, lo que nos hace especular con su posible intervención en la venida de Brunet.

Sabemos que el 17 de abril de 1910 se subastan los solares de la derecha de la calle Chacel que aún estaban por construir, consecuencia del Plan de Urbanización de José de la Gándara - no olvidemos este nombre - de mayo anterior. Inmediatamente comienza a levantarse, con proyecto de Nieto, el edificio que ocupa el $n^{2} 2$ de la Avenida, terminado al afio siguiente.

Aquí es preciso hacer un inciso que aclare la pretendida intervención de Nieto en 
los planes de urbanismo de Melilla. No hay tal. En realidad Nieto no llegó a intervenir en ninguno, pues cuando él falleció aún estaba prácticamente en vigor el de 1928, confeccionado cuando él no era todavía arquitecto municipal, plan de urbanización que, como todos los que en Melilla han sido, no fue llevado a la práctica más que muy parcialmente.

A la llegada de Nieto a Melilla, estaba ya aprobado el plan de construcción del centro urbano, del Capitán Redondo, con fecha 7 de septiembre de 1906, plan que dio lugar al actual barrio Héroes de España, y que, muy al contrario de lo que se sucle pensar al respecto, no tiene nada que ver con influencias catalanas ni alemanas, puesto que D. Euscbio Redondo Ballester, con una idea elementar sobre la cuestión, se limitó a dividir en solares el terreno que le dejaron, que es el que ocupaban los antiguos huertos de la guarnición, es decir el comprendido dentro del triángulo formado por las antiguas carreteras del Buen Acuerdo (hoy calle General Marina), carretera de Polígono (hoy, parcialmente, Avenida) y la carretera de unión entre los dos barrios citados. Agradezcamos que los ingenieros militares no tuvieran intereses personales en aquella empresa y nos legaran unas calles amplias y soleadas, circunstancia ésta, por cierto, criticada por otros arquitectos en los años cuarenta, para quienes tal amplitud constituía un derroche de via innecesario.

Curiosamente, Nieto era un empecinado enemigo de la intervención de ingenieros militares en cuestiones de urbanismo, pues consideraba que se trataba de intrusismo profesional. A este respecto, hemos de darle la razón a nuestro personaje, pues efectivamente, por R.O. de mayo de 1902 los arquitectos titulados tenían la exclusiva en la intervención de obras de carácter civil, por lo que el artículo 62 del Reglamento de la Junta de Arbitrios, aprobado el 12-6-1902, que reservaba la plaza de arquitecto (disfrazándola de ingeniero) para un ingeniero militar, era claramente ilegal. Esta fue una lucha que sostendría parte de su vida y que no vería satisfecha hasta 1930. ¿Cómo hubiese sido la Melilla, actual de haber entrado Nicto como arquitecto municial en 1909? Que cada cual saque sus conclusiones.

En su vida de ciudadano, no era Nieto partidario de relacionarse con los prohombres de la ciudad, lo que constituía una rareza en aquellos tiempos para un titulado superior. Por eso resulta chocante, dada su importante profesión, no encontrar su nombre asociado a ninguna de las directivas de los múltiples organismos privados u oficiales que proliferaban entonces por Melilla, si exceptuamos su corta relación con la Asociación General de Caridad, Hípica, y, sobre todo, con la Cámara de Comercio, de la que primeramente fue bibliotecario hasta 1921 y socio colaborador posiblemente hasta su fallecimiento. Precisamente fue él quien, desde 1913, proyectó y dirigió las obras del nuevo edificio de la Cámara.

Uno de los proyectos de importancia llevado a cabo por esta época es el de la reforma de la fachada, repito "fachada", del Economato Militar, el famoso edificio del $\mathrm{n}^{\mathbf{2}} 7$ de la Avenida, edificio que se le adjudicó en concurso de proyectos, en febrero de 1914, y que fue terminado un años más tarde. Aún permanecen las letras $\mathrm{E}$ y $\mathrm{M}$, indicativas del Economato, aunque la letra $E$ haya sido mutilada no sé si por la acción del tiempo o por la acción del hombre.

Nada más terminar este proyecto trabaja en el importante de levantar dos pisos más al ya citado de la "Reconquista", negocio que había prosperado durante los hechos mi- 
litares mencionados, ejemplo de un hacer habitual en la ciudad, pues la mesocracia melillense, a medida que los negocios subian, subian a su vez los pisos de los cuales eran propietarios; esa es la explicación de las diferencias de detalle que se obsevan en algunas construcciones. Los pisos se elevan con diferencias de algunos años, en función de las rachas de prosperidad económica, fundamentalemtne basadas en el reinicio de las operaciones militares.

Por esta época es nombrado arquitecto consultor de la recién creada Compañía Española de Colonización, empresa que levantaría unos curiosos edificios en el poblado de Monte Arruit que ignoro si serían proyecto de Enrique Nieto. Desgraciadamente, en estos años tanto el urbanismo en general como la construcción urbana en particular no levantaban el entusiasmo que se aprecia en algunos ambientes y las reseffas al respecto son muy escasas, por lo que gran parte de la obra de Nicto ha de quedar para siempre en el anonimato, si no ocurre un milagro que lo desvele.

En 1915, David Melu, dueño del inmueble $n^{2} 1$ de la Avenida, es obligado, por imposición de la Junta de Arbitrios, a alinear el edificio con relación a la recién terminada Plaza de España, afortunada creación de José de la Gándara. Una vez derribado aquél se procede a levantar el actual, proyecto de Nicto, terminado a finales del año siguiente.

Durante los años 1915 a 1918 se levantan también el interesante grupo de edificios del barrio Gómez Jordana. Es en esta época cuando se habla de la "obsesión por la escayola, según ideas llegadas de Cataluña", en clara alusión al arquitecto Nieto. Ni que decir tiene que no son de Nieto todo ese cúmulo de edificios que por error se le atribuyen por el simple hecho de tener características similares a otros del arquitecto. Las reseñas al efecto, extraídas de la época, son contundentes. Entre ellas, la de Francisco Carcaño, ingeniero militar y melillense, autor de varios proyectos en la ciudad y, en su momento, ingeniero de la Junta de Arbitrios, quien hace mención al hecho de que buena parte de los edificios de Melilla fueron construidos directamente por sus dueños, y los más sin intervención de arquitecto ni aparejador, ni siquiera maestro de obras, dejándolos en manos de simples albañiles más o menos hábiles, todo ello consentido, con no disimulado enojo de personas, entre ellas Nieto, que abogaban por que la Junta de Arbitrios y más tarde el Ayuntamiento obligara a tomar arquitecto y aparejador para todas las edificaciones.

Los albañiles y maestros de obras, por supuesto, tomaron la idea del arquitecto catalán y no tuvieron inconveniente en llenar las fachadas de molduras, molduras que fueron repetidamente colocadas en los edificios más diversos como puede colegirse de los trabajos interesantes de mi amigo Antonio Bravo. Más que de escuela yo hablaría de copia o imitación, aunque, si se quiere, pueda ser más o menos lo mismo.

En 1918, Nieto se encarga de la ampliación del Casino Español, casino que ampliaría en dos pisos más en 1924.

La campaña de 1921, trágica por muchas razones, fue un momento de euforia económica para Melilla, momento en que se hicieron los más rápidos y buenos negocios. Esto se ha de notar, como ya he apuntado antes en un crecimiento desordenado de barrios exteriores, verdadero cinturón de pobreza, pero también en un crecimiento en altura de edificios previamente construidos, a los que añade unos, dos o tres pisos según las posibilidades del propietario.

En noviembre de 1923, al hablarse de un posible nombramiento de un arquitecto 
civil para la Junta de Arbitrios, Enrique Nieto eleva una solicitud solicitando la plaza, instancia que le fue denegada, continuando un ingeniero militar desempeñando el cargo. Cuatro años más tarde, en 1927, volverá a insistir en el tema, ofreciendo incluso sus servicios gratuitos, siendo nuevamente rechazado.

En 1924 se inaugura la capilla del Colegio de los Hermanos, proyecto de Nieto. Al año siguiente confecciona, proyecto no llevado a cabo, el de la estación monumental que la Companía Española de Minas del Rif se había comprometido a levantar, cerrando por el Este la Plaza de España.

Son años estos de tremenda desgracia familiar para el arquitecto quien, lo mismo que en 1917 había visto morir a su primcra mujer, ve a su vez, fallecer a tres de sus hijos en el corto espacio de una semana, lo que quizá nos proporcione un acercamiento a su difundido carácter taciturno y, en algunos casos, huraño, pues no sería la última tragedia familiar a la que tendría que hacer frente.

En esta época, muy al contrario a lo que indica Tarragó en su trabajo mencionado, comienza en Melilla el tiempo de una crisis económica que se iría acentuando en los finales de los años veinte, se mantendría activa durante todos los treinta y se iría amortiguando finalizando los cuarenta.

En 1928, auspiciado por Cándido Lobera, presidente efectivo de la neonata Junta Municipal, se convoca - por fin - una plaza de arquitecto municipal, con el fin de deslindar definitivamente la parte urbanística de la de obras generales. Al concurso se presenta, junto con Nieto, el ya curtido Mauricio Jalvo, arquitecto con buen currículum, pues había sido arquitecto municipal de Madrid y algunas capitales sudamericanas. Al decantarse el voto general de los integrantes de la Junta por el último, Nieto sufre una gran decepción que, en mi opinión, debió marcarle profundamente para el futuro. Aunque recurre, llegando hasta el Supremo, pierde el recurso.

Comienza entonces una lucha sorda entre los dos arquitectos, ambos con criterios distintos sobre la ciudad, lucha que continuaría dos años más tarde cuando Nieto entre, por fin, en el Ayuntamiento recién creado, en sustitución del ingeniero militar Moreno Lázaro, fallecido ese año. Pero, nuevo motivo de decepción, le está vedado intervenir en la edificación, quedando a cargo de obras varias mientras Jalvo se encarga de aquellla. Los conflictos de competencias y la divergencia de pareceres son continuos, dando lugar a situaciones incómodas para ambos. Como ejemplo diremos que Mauricio Jalvo acusaba a Nieto de querer cambiar la Ordenanza municipal sobre construcción para sacar dos viviendas de donde sólo salía una, aludiendo a su falta de interés, por los interiores.

Durante los años treinta la construcción decae notablemente con relación a los años anteriores. Sin embargo es en esta época cuando Nieto levanta edificios que hoy son considerados como singulares dentro de su obra.

En 1929 había levantado lo que sería su domicilio particular en la calle Pedro Antonio de Alarcón. En 1930, derribado el anterior de madera, levanta el Teatro Kursaal, hoy Cine Nacional. Tres años más tarde finaliza, sobre el solar que deja el, antiguo Teatro Reina Victoria, el edificio de $\mathrm{C}$. Cándido Lobera propiedad suya.

Mauricio Jalvo se jubilará en 1932 quedando Nieto como único arquitecto. Los conflictos con aquel se traspasan ahora a la Corporación municipal, siendo repetidos los choques con algunos de los hombres del nuevo Ayuntamiento, quizá por incompa- 
tibilidad ideológica. Se llegó, en algún momento, hasta supenderle de empleo y sueldo. Es precisamente, en esta época, 1933, cuando confecciona su proyecto de nueva casa municipal, que luego sería elegido entre varios al efecto. Comenzados los cimientos en 1940, se terminaría, previas reformas internas, el ano 1949 para satisfacción de todos y singularmente del autor que dejaría así su obra más monumental como canto del cisne del que había dedicado gran parte de su vida a la ciudad de Melilla. Esta, sin embargo, no fue, quizá lo suficientemente agradecida a su arquitecto, pues cinco años más tarde, en 1954, fallecería Enrique Nieto, sorprendiendo que en su reseña mortuoria en la prensa local, apenas se den unas pocas, poquísimas líneas sobre el óbito, sin la más mínima glosa de su vida y obra, con olvido total de lo que Nieto había supuesto para la ciudad de su manifestación arquitectónica. Sic transit gloriae mundi.

Estos son algunos rasgos sobre la vida y obra de Enrique Nieto, rasgos que por falta de espacio han de quedar necesariamente reducidos e incompletos, y que sólo pretenden ser una modesta contribución al conocimiento del gran arquitecto. 